\title{
Simulating orographic rainfall with a limited-area, non-hydrostatic atmospheric model under idealized forcing
}

\author{
A. Pathirana ${ }^{1}$, S. Herath ${ }^{1}$, and T. Yamada ${ }^{2}$ \\ ${ }^{1}$ United Nations University, Tokyo \\ ${ }^{2}$ Chuo University, Tokyo
}

Received: 26 July 2004 - Published in Atmos. Chem. Phys. Discuss.: 22 September 2004

Revised: 14 December 2004 - Accepted: 14 December 2004 - Published: 27 January 2005

\begin{abstract}
A modified version of an operational 3dimensional, non-hydrostatic, limited-area atmospheric model (MM5) was used to perform high-resolution, idealized simulations of the interaction of an infinitely long single ridge with a steady, lateral large-scale wind field. The effect of different mountain ridge dimensions, wind speeds and patterns and moisture profiles on the quantity and distribution of orographic rainfall was investigated. The simulations demonstrated a number of commonly observed mountain flow features like formation of cap clouds, foehn wall, convective break-out associated with mountain topography, interaction of downslope winds with sea breeze, and different stages of cumulus development. It was found that the rainfall maxima associated with the mountain always occur upstream of the ridge peak. Changing mountain dimensions, wind speeds and patterns and moisture profile had clear effects on amount and pattern of accumulated rainfall. Low wind speeds resulted the maximum accumulated rainfall to occur considerable distance upstream of ridge peak. Reversal of wind directions in upper atmosphere caused rainfall to be largely restricted to the wind-side of the peak. The observed rainfall patterns are explained by the different flow patterns observed in the model output.
\end{abstract}

\section{Introduction}

Rainfall prediction remains among the toughest challenges ever faced by modern science. While the physics of most of the processes involved in atmospheric dynamics has been long understood, the interaction of the different processes combined with the complexities of underlying terrain results in a system that is extremely hard to capture. One traditional approach to comprehend the atmospheric processes is the use

Correspondence to: A. Pathirana

(pathirana@hq.unu.edu) of simplified systems whose solutions can be found by theoretical means (Gossard, 1975; Holton, 1992; Houze, 1993). Another relatively new technique is using numerical models which represent the physics of atmospheric processes at the grid level (Pilke, 2002). Usually the former helps the analyst to have insights into behavior of physical laws in very much simplified contexts, while the latter is more often used for the analysis of the real atmosphere and forecast of weather for research and operational purposes. Physical simulations with many model descriptors and boundary conditions idealized, can be seen as a compromise between the above two approaches. Idealized physical simulations can be used to introduce the conditions of actual atmosphere into a numerical model in a controlled manner, thus making it possible to isolate them from the other complexities of the real atmosphere for a closer study (e.g. Doyle and Durran, 2001; Nance and Durran, 1997, 1998).

Interaction of large topographical features with a wind field has dramatic effect on the generation of rainfall. It is observed and widely accepted that mountainous terrain generally receives more rainfall than lowland in the same geographic region and as a result there is a general positive correlation between elevation and average rainfall yield at large time accumulations. Rainfalls in the world's most rainy climates are determined by the different atmospheric mechanisms that are critically dependent on the presence of mountainous terrain, making the knowledge on orographic rainfall a much needed ingredient of strategic planning on sustainable use of water resources or on water related disaster mitigation. Water availability of world's major rivers depend on the rainfall occurring on mountainous watersheds.

The airflow over a mountain ridge is a problem that has been subjected to extensive theoretical investigation (see Smith, 1989, for a review) and more recently to a number of numerical studies involving both real and idealized settings. Sufficiently simple systems can be arrived at by utilizing Boussinesq approximation (air density is treated as

(C) 2005 Author(s). This work is licensed under a Creative Commons License. 
constant except in buoyancy) and linearizing about a hydrostatic base state (Holton, 1992). Hibino et al. (1993) used linear theory (frequency domain analysis) to study the flow above a ridge. They investigated the range of internal Froude number that generates trapped lee waves and reported that the flows with small internal Froude numbers that are not strong enough to flow above the ridge top, generates stagnation points on the lee-side. However, often many important features of mountain flow are associated with rotors, large-amplitude waves and other non-linear phenomena so that the linearized-Boussinesq systems fail to represent them adequately. The use of non-hydrostatic numerical models is a preferred choice in the situations where the linearity approximation is not viable. In the recent literature, several studies using limited-area non-hydrostatic models to examine various aspects of the problem of flow over a mountain ridge have appeared. Nance and Durran $(1997,1998)$ investigated the effects of unsteady background flow on lee wave behavior using a fully compressible model developed by Durran and Klemp (1986). Pathirana et al. (2003) used a 3-dimensional mesoscale model (MM5) for similar purposes. Doyle and Durran (2001) used the two-dimensional version of the Coupled Ocean-Atmospheric Mesoscale Prediction System (COAMPS) developed by U.S. military to investigate the dynamics of rotors associated with the lee waves. They observed that there is a threshold value of ridge height, only above which the flow separation due to rotors will occur. Those idealized studies have focused on the dynamics of dry air, without incorporating the phase change of water substance and the rainfall generation.

This paper presents a series of idealized numerical experiments conducted to elucidate the atmospheric flow past a single mountain ridge and the resulting modification of rainfall and related microphysical phenomena. The objective was to understand the effect of different topographic and atmospheric parameters on the rainfall due to the interaction of topography with large-scale wind fields. Mountain dimensions, wind speeds and moisture profile were each varied while keeping all the other parameters constant and the resulting changes in rainfall quantity and patterns were investigated. Rain clouds were explicitly resolved to demonstrate a number of classic atmospheric phenomena that are important to understand orographic precipitation. An effort was made to identify conditions under which the rainfall is mainly limited to the wind side of the ridge, causing rain-shadows in the leeward slopes.

Section 2 describes the numerical modeling system used for the study and the special modifications/enhancements required to perform idealized simulations. Then the details of different numerical experiments are given in Sect. 3. The results of those experiments are discussed and reasoned in Sect. 4 and finally conclusions are stated in Sect. 5

\section{Idealized simulation system}

\subsection{MM5 Model}

The fifth generation Pennsylvania State University/National Center for Atmospheric Research mesoscale model, MM5 (Dudhia, 1993; Grell et al., 1996) solves a fully compressible, non-hydrostatic set of governing equations (for prognostic variables of velocity, pressure perturbation and temperature) on a terrain following $(\sigma-z)$ coordinate system. The model requires the specification of the initial conditions all over the modeling domain and the lateral boundary conditions during the whole time period of model integration. Boundaries need to have specified horizontal winds, temperature, pressure and moisture conditions and optionally microphysical fields. In an operational scenario, the lateral boundary data are usually obtained from global scale model results or analyses at some intermediate spatial scale, which ultimately depend on a global model. Additional observations like radiosonde data and surface reports can be used to improve initial/boundary conditions.

The boundary conditions of the MM5 model are imposed using the so-called relaxation/inflow-outflow scheme. A five cell thick layer all around the rectangular model domain are affected by the lateral boundary conditions. The outermost layer (consisting of two rows and two columns) is specified by the time-dependent boundary condition value. The next four inner layers are relaxed toward the model values from boundary values, with a relaxation constant that decreases linearly away from the boundary.

Performing idealized simulations is not a standard usage of the modeling system and therefore a number of additional modifications of the preprocessing programs are needed before the model can be used for the purpose similar to the one of the present research. However, there are a number of distinct advantages in using MM5 as the basis for an idealized study. The model has been in operational and research use worldwide for more than a decade, resulting in a welltested numerical system. It's source code is freely available for use. Further, due to the model's ability to perform simulations based on real observational data and large-scale model outputs with relative ease, it is feasible to extend the ideal simulations to those using real data in future work, without switching models.

The available preprocessor programs of MM5 model sets up the model grid including surface topography and other land-surface features using standard geographical datasets like GTOPO-30 elevation data and 24-category landuse data of United States Geographical Survey. They produce initial and lateral forcings using standard three dimensional pressure level datasets (first-guess fields) together with surface observations and soundings. In order to perform idealized simulations both these steps have to be altered to ingest idealized conditions. 


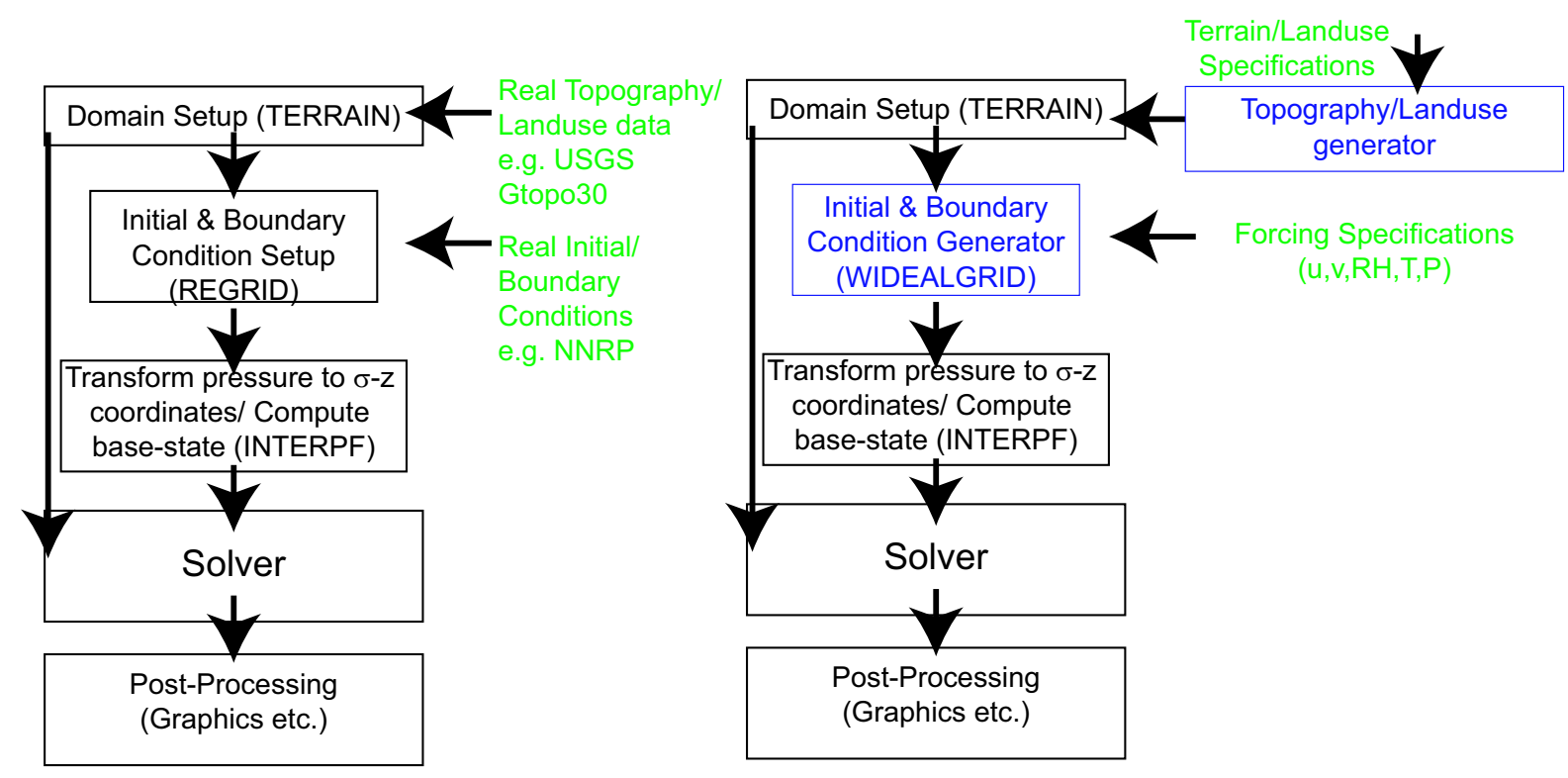

(a) Typical MM5 modeling system operation

(b) Idealized MM5 operation

Fig. 1. Differences between original MM5 modeling system and the present modification. Modules that are not present in original system are shown in blue color

The MM5 model has a number of options for selecting different physical packages to represent different processes. Some of these selections for the present set of simulations are discussed in Sect. 3.

\subsection{Required Modifications}

There have been two successful attempts to develop systems to generate idealized terrain and boundary/initial conditions for MM5 model: Leutbecker (1996) developed the Terraini/Datagridi system to generate terrain data for a number of two and three dimensional terrain types and userspecified idealized initial/boundary conditions for the version 2 of the MM5 model. Later Rögnvaldsson (2002) introduced idealgrid system to generate idealized forcing for version 3 (current version) of MM5. These were limited to dry-simulations. We have developed the present idealized simulation package to incorporate moisture fields into the initial/boundary conditions so that the model can simulate idealized rainfall. Figure 1 shows the main differences between operational version of MM5 system and the present idealized one.

In the present setup, a routine was developed to create artificial datasets conforming to the data format of GTOPO30 topographical data and USGS 24-category landuse data, with the desired idealized topography and landuse features. These datasets were made available for the standard preprocessor program. With this approach the need to reprogram the model domain setup preprocessors (TERRAIN) is eliminated.
The velocities in $x$ and $y$ directions ( $u$ and $v$, respectively), temperature and humidity profiles are specified for different pressure levels, and the geopotential height is computed to obtain a hydrostatically and geostrophically balanced input dataset for MM5. Layer thicknesses in terms of geopotential height is computed using the following relation derived from hydrostatic equation $(-d p=g \rho d z$, where $\rho$ is density)

$$
\left(Z_{2}-Z_{1}\right)=\frac{R_{d}}{g_{0}} \frac{\log \left(P_{1} / P_{2}\right)\left(T_{v 2}-T_{v 1}\right)}{\log \left(T_{v 2} / T_{v 1}\right)}
$$

for lower layers where $T_{v} \approx T_{v 0}-\Gamma^{\prime} Z$ and

$$
\left(Z_{2}-Z_{1}\right)=\frac{R_{d}}{g_{0}} T_{v} \log \left(P_{1} / P_{2}\right)
$$

for isothermal layers

where $R_{d}, g_{0}, \Gamma^{\prime}$ are dry gas constant, globally averaged gravitational acceleration and lapse rate of temperature with height, respectively. $T_{v}$ is virtual temperature defined by

$T v=T\left[1+0.61\left(w_{s} \frac{R H}{100}\right)\right]$

where $w_{s}$ is the saturation mixing ratio of water and $R H$, relative humidity. Saturation mixing ratio can be computed from saturation vapor pressure $\left(e_{s}\right)$ as : $w_{s} \approx 0.622 e_{s} / p$. The present system uses the sixth order polynomial equation proposed based on experimental results, by Flatau et al. (1992):

$e_{s}=\sum_{i=0}^{6}\left[a_{i}(T-273.15)^{i}\right]$

where $a_{i}$ are constants. 


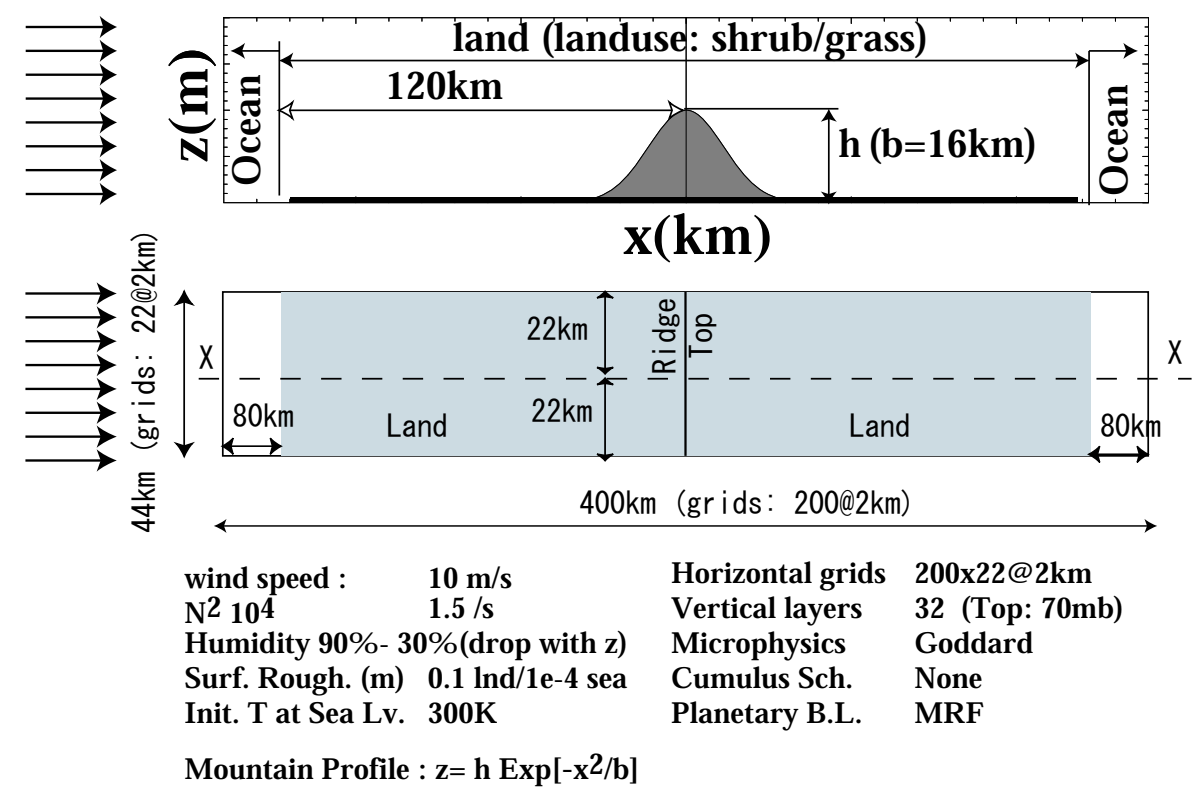

Fig. 2. Common details of the simulation setup. Top: Vertical section. Middle: Plan view. Bottom: Important model settings.

Table 1. Temperature (T) and moisture profiles (M.P.). Relative humidity given in percentages.

\begin{tabular}{lrrrrrrrr}
\hline P (hPa) & 1000 & 950 & 850 & 700 & 500 & 400 & 300 & 100 \\
T (K) & 300 & 298 & 293 & 284 & 269 & 259 & 246 & 200 \\
M.P. I & 95 & 95 & 95 & 95 & 80 & 75 & 50 & 30 \\
M.P. II & 95 & 95 & 85 & 80 & 75 & 40 & 30 & 30 \\
M.P. III & 90 & 85 & 70 & 60 & 50 & 40 & 30 & 30 \\
\hline
\end{tabular}

In order to minimize the development of spurious accelerations due to unbalanced Coriolis forces, the pressure fields should be adjusted to be geostrophically balanced. In the present system, this is done by adjusting the surface geopotential height by adding a Coriolis correction factor $(\Delta Z)$ : The correction at the center of the model domain is taken as zero and for other points the value is computed as:

$\Delta Z=\frac{f}{g_{0}}(-u \Delta x+v \Delta y)$

where $f=2 \Omega \sin \phi$ (Coriolis factor) where $\Omega$ and $\phi$ are angular velocity of earth and latitude, respectively. $\Delta x$ and $\Delta y$ are the offsets from the central point.

The dynamical problem of the interaction of a single long mountain ridge with lateral wind is essentially a two dimensional one. In order to use a 3-dimensional model with computational economy, a long, thin model domain was adopted. However, due to the use of relaxation boundary condition, the smaller of the two domain dimensions can not be made arbitrarily small. Further, in order to simulate important atmospheric processes like convective cloud development properly, a minimum breadth is required. After some initial ex- perimentation a value of 22 grids $(44 \mathrm{~km})$ was used. In the following sections the results are produced along the cross section $\mathbf{X}-\mathbf{X}$ (central line, see Fig. 2) unless otherwise stated. This is the row that is least affected by the boundary effects. The possible effect of boundaries on the results are discussed in Sect. 4.

\section{Simulations}

Figure 2 and Table 1 show the important model parameters. Due to the possibility of cloud formation at relatively high altitudes under tropical conditions, the model top was selected at $70 \mathrm{mb}$ (about $16 \mathrm{~km}$ ). Vertical distance was divided into 32 layers of unequal thickness (Starting with a small value near surface and gradually increasing thickness with elevation). Since the grid size is relatively small $(2 \mathrm{~km})$, it is desirable to neglect the cumulus parameterization (Pilke, 2002), leaving the explicit resolving of moisture as the only rainfall mechanism. Here, the Goddard Mixed-Phase scheme, which predicts ice, snow and graupel in addition to cloud water, rain water and vapor states (Tao et al., 1989; Lin et al., 1983) was used. The planetary boundary layer was modeled using the MRF scheme also known as Hong and Pan PBL (Hong and Pan, 1996). The temperature profile was selected such that the Brunt-väisälä frequency $\left(N^{2}=g / T\left[\partial T / \partial z+g / C_{p}\right]\right)$ for dry air, (see Durran and Klemp, 1982, for several definitions for moist air, ) is roughly a constant value of 0.012 $\left(N^{2} \times 10^{4} \approx 1.5\right)$. The effects of clouds and diurnal cycle on atmospheric radiation were taken into account. The model was integrated at $6 \mathrm{~s}$ time-steps producing output at every $10 \mathrm{~min}$. 


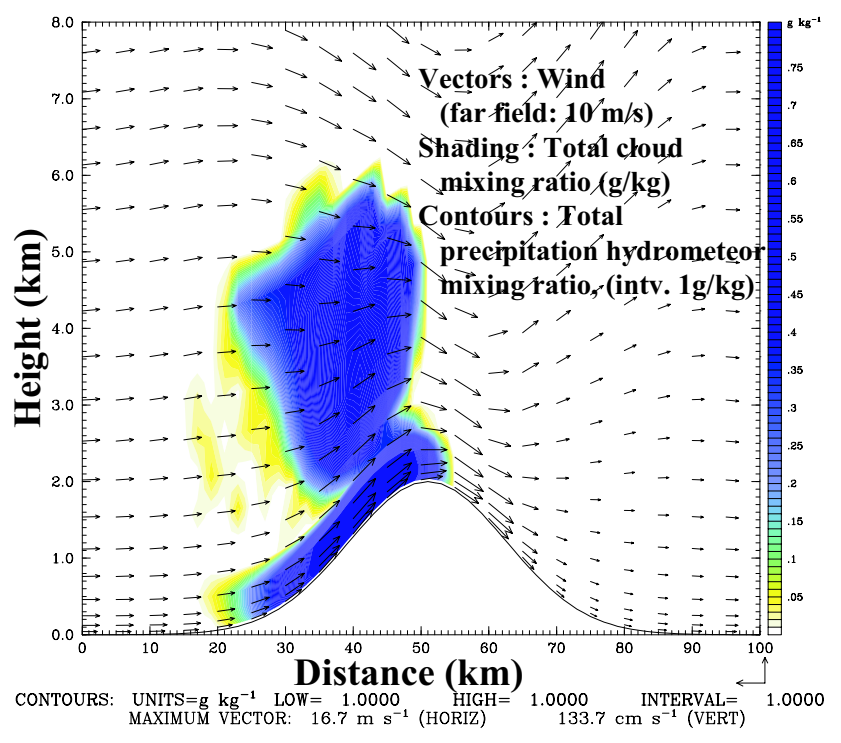

Fig. 3. Cloud development after 10 min of model start.

In order to understand the effects of various topographic and atmospheric factors a number of simulations were done with different model parameters. The first model run (hereafter referred to as the control run) was conducted using a mountain with $H=2000 \mathrm{~m}$ and $b=16 \mathrm{~km}$. The wind condition was set at $10 \mathrm{~m} / \mathrm{s}$, constant with height. The moisture profile was such that the lower layers are nearly-saturated $(R H>90 \%)$ and then dropping to a value less than $30 \%$ above $450 \mathrm{hPa}$ level (M.P.I). Table 1 lists the temperature and moisture profiles used.

Several minutes after the model initialization, the clouds first start to appear above the wind-side slope of the mountain. These clouds are of very low altitude (only several hundred meters above mountain surface). Figure 3 shows the cloud structure after $10 \mathrm{~min}$ of model start. The low-level cloud's base is at the level of the surface, so that this type of clouds may appear as fog to an observer on the mountain top. These clouds, due to their appearance as a wall to an observer on the lee-side, are known as a foehn wall and are generally non-precipitating due to their lower elevation (Houze, 1993; Wallace and Hobbs, 1977). However, low-elevation clouds can sometimes precipitate by working together with clouds aloft that are capable of providing large precipitation particles (Houze, 1993). Though the simulation has generated a high-elevation cloud system aloft, there is no precipitation formed at this time. Small amounts of rainfall $(<1 \mathrm{~mm} / 10 \mathrm{~min}$ ) start to form after about $20 \mathrm{~min}$ of model start. However, significant amounts of rainfall (e.g. $>2 \mathrm{~mm}$ ) occur only after the start of convective development. (i.e. about $1 \mathrm{~h}$ after model start.)
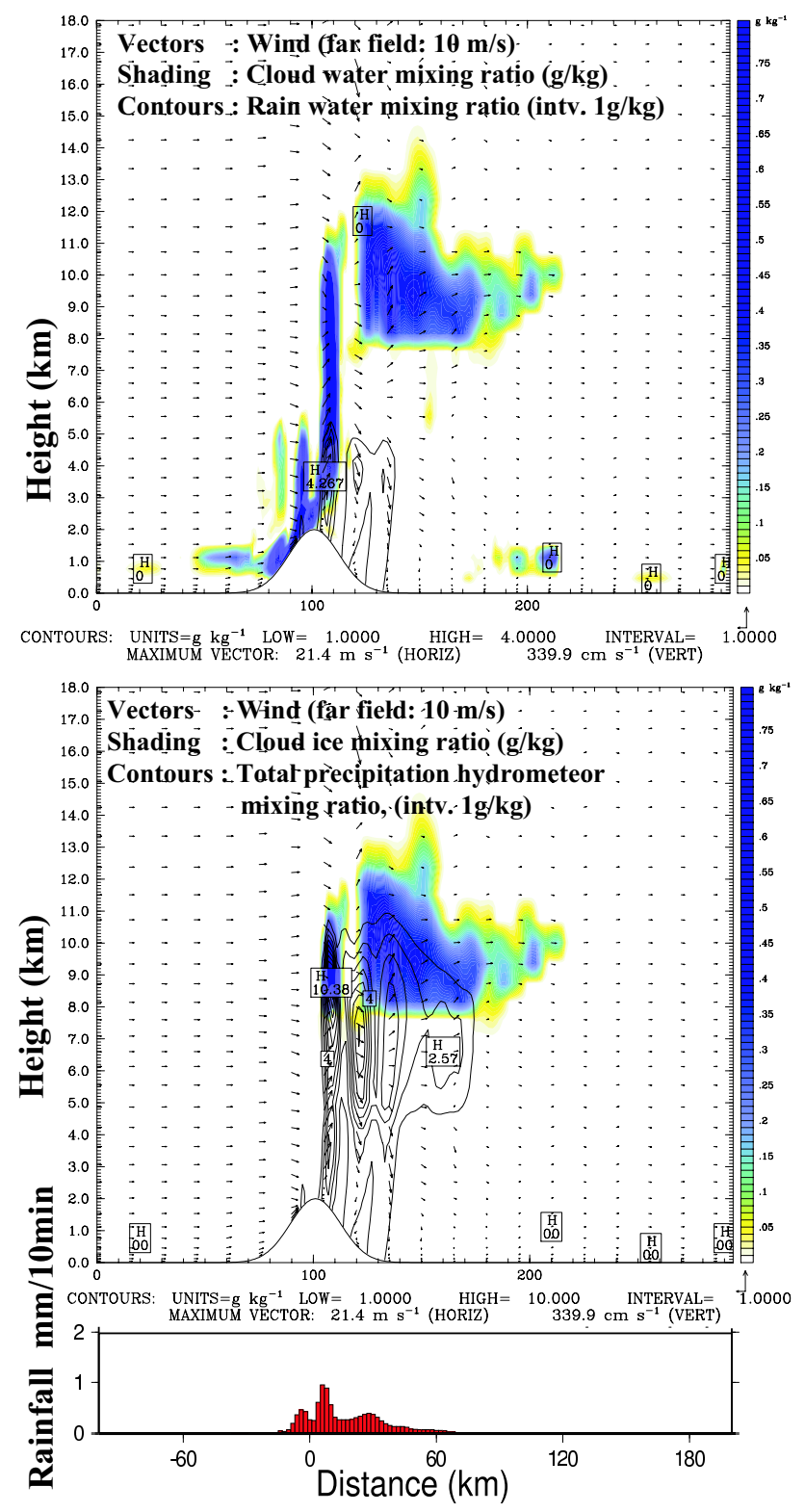

Fig. 4. Development of clouds (200 min after start) and the corresponding rainfall. Top: cloud water mixing ratio and rain water mixing ratio. Middle: cloud ice mixing ratio and total precipitation hydrometeor mixing ratio. Bottom: rainfall during the next 10 min period.

During the next several 10 min periods, the clouds develop rapidly in height aided by convective break-out due to the combined effect of topography and land-heating. In atmosphere, these dense clouds with sharp outlines that develop vertically in the form of rising mounds (Cumulus) later develop into Cumulonimbus under favorable conditions. $\mathrm{Cu}-$ mulonimbi are often characterized by the development of an anvil - the top part of the cloud that develops rapidly in the direction of wind. Figure 4 shows the development of anvil 
Table 2. Model parameters used for different experiments.

\begin{tabular}{|c|c|c|c|c|c|c|}
\hline \multirow[t]{2}{*}{ Code } & \multirow[t]{2}{*}{ Parameter(s) varied } & \multirow[t]{2}{*}{ Value for control Run } & \multicolumn{4}{|c|}{ Experiment } \\
\hline & & & $\mathbf{a}$ & b & c & d \\
\hline $\mathbf{H}$ & Ridge Height (km) & 2 & 0.5 & 1 & 3 & 4 \\
\hline $\mathbf{W}$ & Width factor, b $(\mathrm{km})$ & 16 & 4 & 32 & 64 & \\
\hline $\mathbf{U}$ & Wind Speed $(\mathrm{m} / \mathrm{s})$ & 10 & 2 & 5 & 20 & \\
\hline $\mathbf{M}$ & Relative Humidity & M.P. I & M.P. II & M.P. III & & \\
\hline $\mathbf{R}$ & Wind profile/Moisture & Uniform & $\begin{array}{c}\text { Reverse } \\
\text { /M.P. III }\end{array}$ & & & \\
\hline $\mathbf{S}$ & Wind profile/Moisture & Uniform & $\begin{array}{l}\text { No Wind } \\
\text { /M.P. III }\end{array}$ & & & \\
\hline
\end{tabular}

in the control run. It was observed that when the topography is higher, this growth takes place faster (within $2 \mathrm{~h}$ in $2000 \mathrm{~m}$ whereas $500 \mathrm{~m}$ takes about $4 \mathrm{~h}$ ). A significant amount of rainfall starts to appear only after this cloud escalation and anvil development. The rain starts near the peak and then spreads towards the lee-side slope as the clouds spread that way. The precipitation leaves clouds often as snow or ice (see the contours of rain water mixing ratio and total precipitation mixing ratio), but later transformed into liquid rain as it descends to warmer lower levels of the atmosphere. Some of the precipitation never reaches the surface (e.g. about $150 \mathrm{~km}$ downstream of the ridge-peak) and gets re-evaporated during the decent through the atmosphere (virga). While the air aloft is cool and moist enough to generate large amounts of hydro-meteors, the lower reaches of lee side has warm and dry air due to the moisture depletion above the ridge and resulting release of latent heat (classical foehn effect). When the hydro-meteors arrive at these warm reaches, they get promptly evaporated.

In the following sections the effects of changing Mountain height, Mountain width, Wind speed, Moisture profile and Wind profile, on rainfall are discussed. Table 2 shows a summary of various experiments conducted. Simulations were performed for the following cases, in addition to the control run: Ridge height $-0.5,1.0,3.0,4.0 \mathrm{~km}(\mathrm{H}-\mathrm{a}, \mathrm{H}-\mathrm{b}, \mathrm{H}-\mathrm{c}, \mathrm{H}-\mathrm{d})$; Ridge width - 4, 32, $64 \mathrm{~km}$ (W-a,W-b,W-c); Wind speeds - 2, 5, $20 \mathrm{~m} / \mathrm{s}$ (U-a,U-b,U-c); Moisture profiles - M.P.II, M.P.III (M-a,M-b, Profiles are given in Table 1). Experiment R-a was done with a vertically varying wind profile with reversal of wind direction above $6 \mathrm{~km}$ height and moisture profile M.P.III. Experiment S-a had no large-scale winds and M.P.III. A large stretch of ocean (about $200 \mathrm{~km}$ ) on the windward and leeward sides were provided in experiment S. In each of those cases, all the parameters except the ones listed in Table 2 were kept equal to those of the control run.

\section{Discussion of Results}

After solving the model for a 24 hperiod, the rainfall amount accumulated over that period was plotted. Figure 5 shows these distribution for all the experiments including the control run.

There are some features of accumulated rainfall that are common to all the simulations performed: The general tendency is that the plains that are further away from the mountain gets relatively less rainfall compared with the slopes. However, non of the cases had the rainfall maxima at the peak of the ridge, but at a point some distance upstream of the peak. This is in agreement with rainfall patterns of some monsoon climates (Zubair, 1999). All the cases using moisture profiles I and II (Table 1) show a significant rainfall amount falling on lee-side plains, in addition to the rain on windward slope and ridge-top. Rainfall amount generally increased with elevation - particularly on the wind-side plane, where most cases showed a nearly linear relationship between rainfall accumulation and elevation (Fig. 6).

The mountain height has a positive correlation with the rainfall: Rainfall peak over the mountain as well as the total rainfall amount increased with ridge height. However, the rainfall amount on the downstream was not significantly affected. The increase of the width of the mountain leads to a decrease of ridge-top rainfall and an increase of rain on leeside. This is contradictory to some of the accepted patterns of orographic rainfall. For example Smith (1979) has stated that wider mountains cause lee-side rain shadows.

The large-scale wind speed has a dramatic effect on rainfall distribution. Wind speeds of $20 \mathrm{~m} / \mathrm{s}$ and $10 \mathrm{~m} / \mathrm{s}$ causes the rainfall peak to occur on the windward slope, quite close to the ridge top. However, it was observed that for low wind velocities $(5 \mathrm{~m} / \mathrm{s}$ and $2 \mathrm{~m} / \mathrm{s})$ this rainfall peak can occur a significant distance upwind of the mountain ridge. For 2 $\mathrm{m} / \mathrm{s}$ case this distance was more than $50 \mathrm{~km}$ from the ridge peak. The overall rainfall pattern shows a distinct waviness, suggesting the possibility of mountain wave action. However, while all the cases generated gravity waves due to the ridge, they are of un-trapped nature progressing nearly 

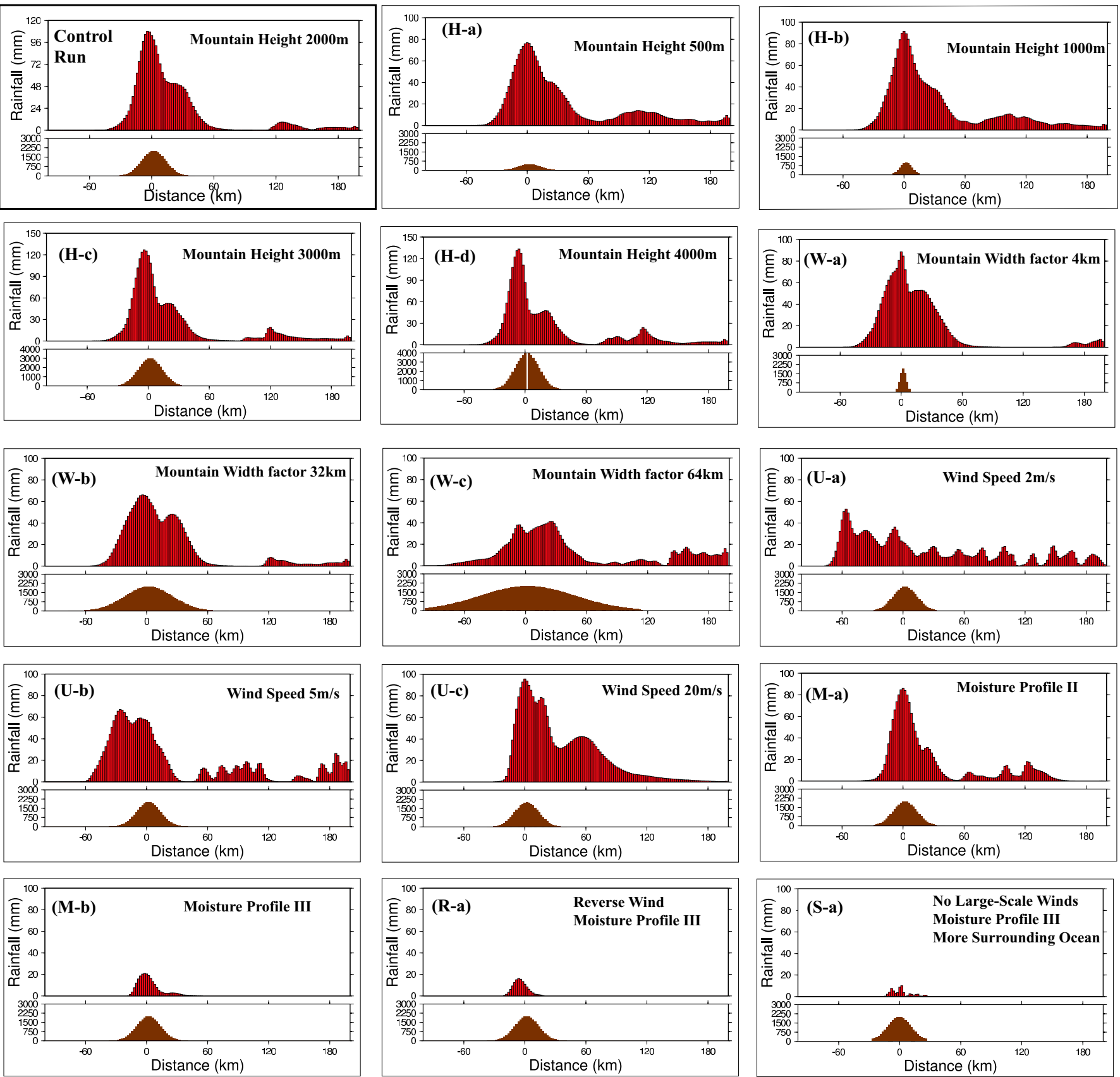

Fig. 5. Distribution of rainfall accumulated over $24 \mathrm{~h}$ period for different cases. Top-left: Control Run. (H-a,b,c,d): Different ridge heights. (W-a,b,c): Ridge width factors $(b)$. (U-a,b,c): Wind speeds. (M-a,b): Moisture profiles. (R-a): Presence of reverse flow in upper atmosphere. (S-a): A case with no large-scale winds. (Corresponding ridge profile is shown below each plot with height in $\mathrm{m}$.)

vertical above the ridge. The cloud structure (Fig. 7) indicates that the rainfall at lower velocities is driven mainly by deep convection triggered due to the flow modification by the mountain as discussed by Houze (1993). Figure 8 shows the contours of horizontal velocity component parallel to the flow-direction for the cases of $2 \mathrm{~m} / \mathrm{s}$ and $10 \mathrm{~m} / \mathrm{s}$ velocities. It clearly shows the occurrence of negative horizontal veloc- ities in front of the mountain for the former case. The flow separation and resulting rotor formation provides an opportunity for the potentially unstable air flowing from upstream to form convective columns quite ahead of the topography. When the wind velocities are sufficiently large, the topography does not cause wind-blocking. 

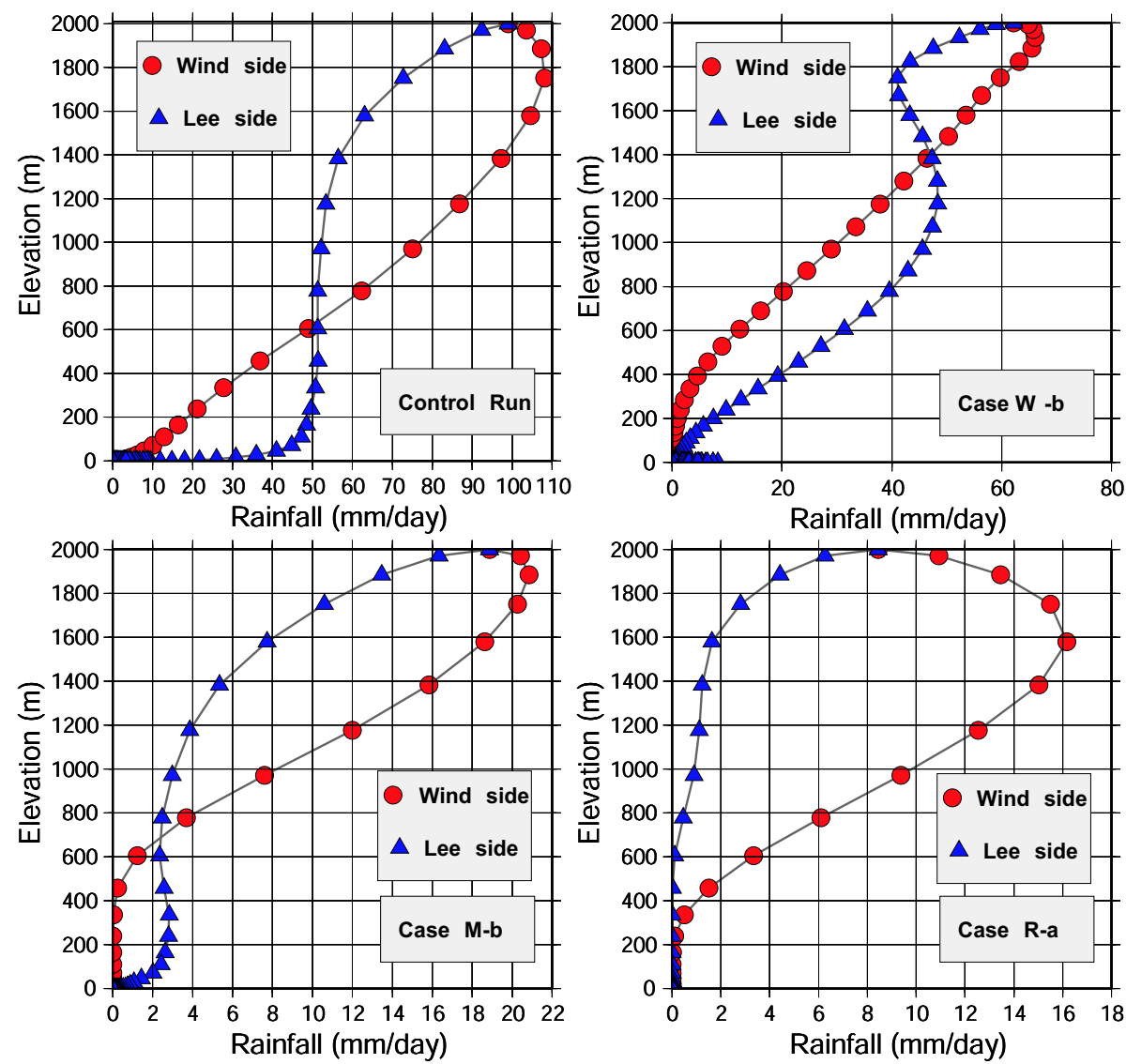

Fig. 6. Relationship between rainfall accumulations and elevation over the mountain ridge. Values for windward and leeward slopes are shown with different symbols.

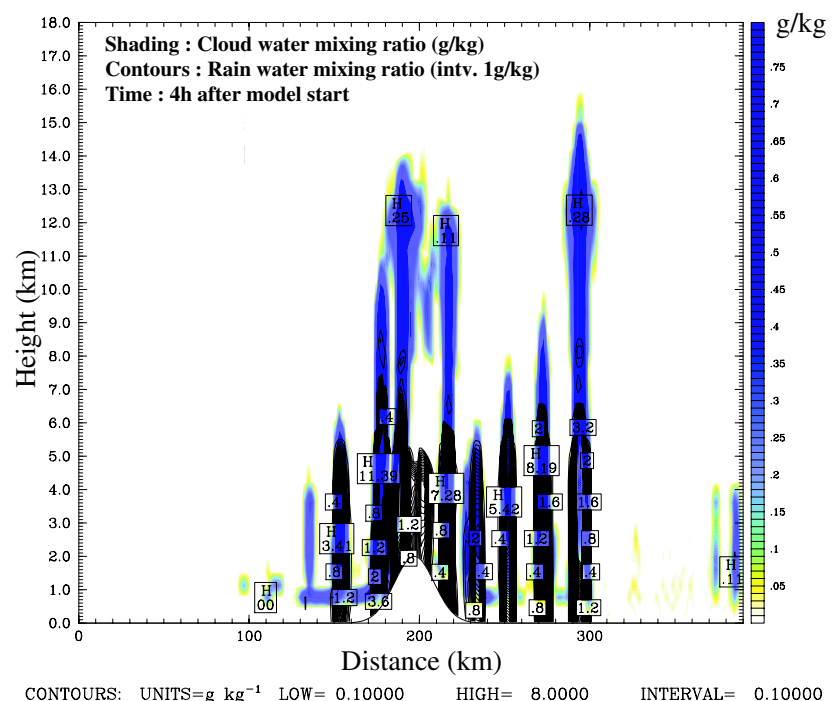

Fig. 7. Clouds and rainfall generated by convection triggered by mountain flow. (Case $\mathrm{U}-\mathrm{a}$ after $4 \mathrm{~h}$ of model start.)
Most of the rainfall accumulations show a second smaller peak on the lee-side of the ridge (e.g. Fig. 5W-a,W-b,U-c) whose occurrence can be attributed to the convection triggered by the interaction of the moist sea-breeze, warmed up over the land with drier and (relatively) cooler downslope wind. Figure 9 shows the wind vectors on the lee-side of the cases M-b and S-a. While the latter case with no large-scale wind-field causes rainfall mostly on the ridge top, the former causes convective clouding and rainfall on lee-side slope.

The drier moisture profiles cause reduction of peak over the mountain top (see Fig. 5M-a,b). However, when the moisture profile is reduced to that of M.P. III (Table 1) the convective rainfall on the lee-side becomes very much restricted (Fig. 5M-b). As shown in Fig. 10, with the low humidity of large-scale flow, the air leaves the mountain ridge top so critically depleted of water vapor that the rainfall does not progress much downstream beyond the ridge top.

The actual wind profile of a location on earth can hardly be invariant with height. Many climatic regions feature reversal of winds and resulting shear at the middle levels of the troposphere. For example, the typical wind pattern during the summer monsoon over the Indian Ocean, is very much different from the constant wind fields used in the preceding 

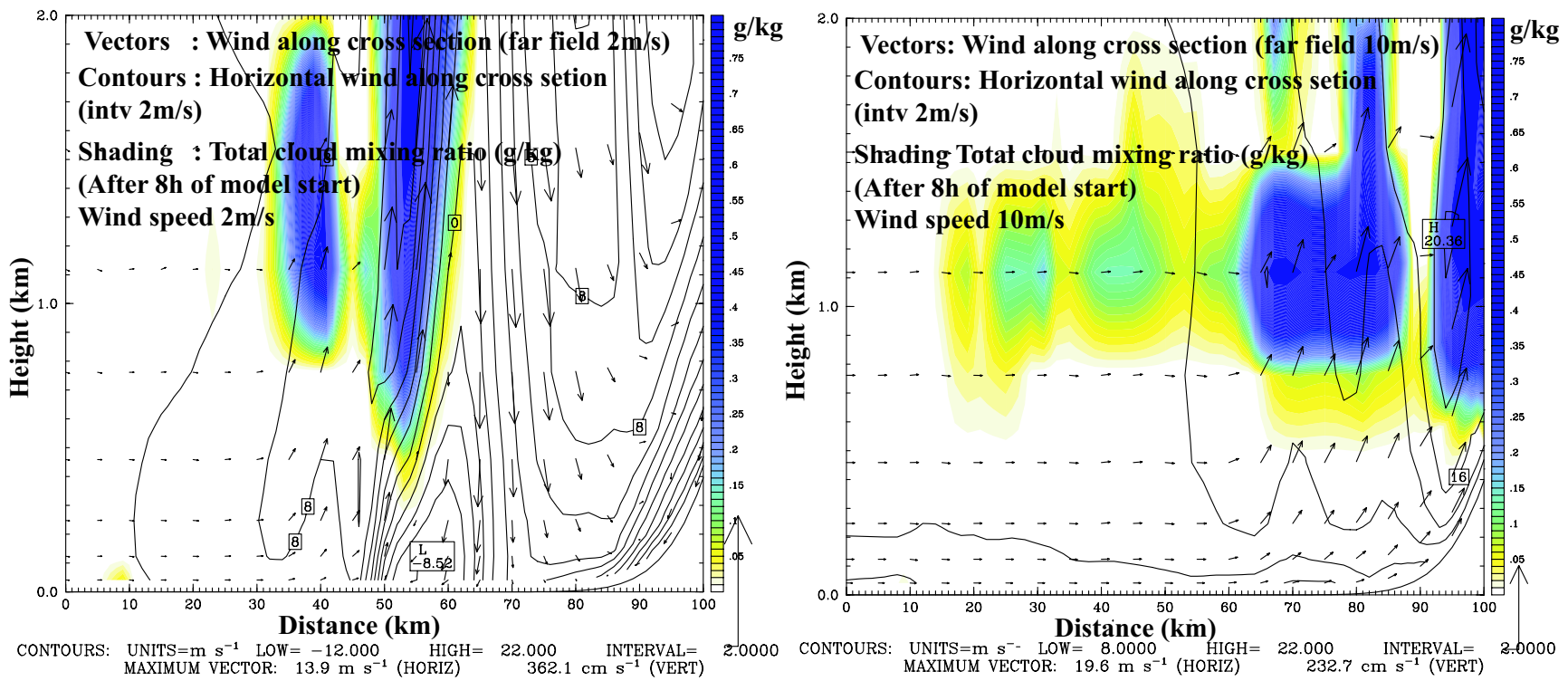

Fig. 8. A close look at the situation upstream of mountain ridge. (A part of the ridge is visible on the bottom right corner.) For slow velocities, topography causes wind blocking. Simulation with $2 \mathrm{~m} / \mathrm{s}$ wind (left) shows clear evidence of flow-reversal as a result of blocking while $10 \mathrm{~m} / \mathrm{s}$ (right) does not.
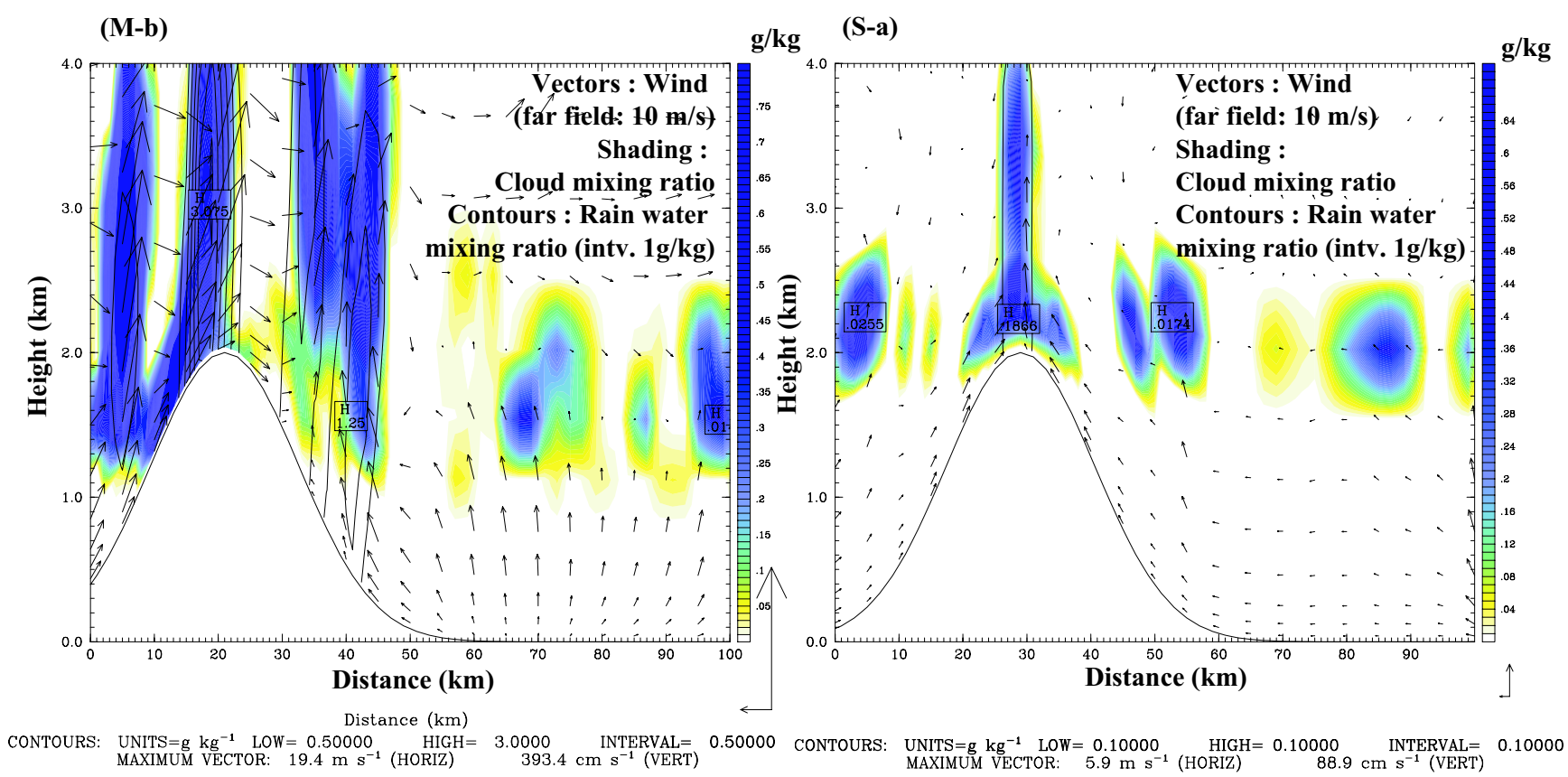

Fig. 9. Situation on the lee-side in the afternoon (13:00 h) for cases M-b and S-a. Combination of sea-breeze and large-scale wind, causes lee-side enhancement of convective activity (left).

analyses. Due to the action of the tropical easterly jet in the upper troposphere, the wind velocities gradually drop from a maximum near surface to a flow in opposite direction above a $6-7 \mathrm{~km}$ height. Figure $5 \mathrm{R}-\mathrm{a}$ shows the results of a simulation with wind reversal above $6 \mathrm{~km}$ height. The rainfall peak has moved further upwind compared with case M-b and there is almost no lee side rainfall. This pattern is quite in agreement with what is happening associated with mountains in some monsoon climates, e.g. Sri Lanka: The summer monsoon enters the island from west and passes through the central mountains, causing heavy rainfall on the western slopes, while the eastern slopes and plains remain relatively 
(a)

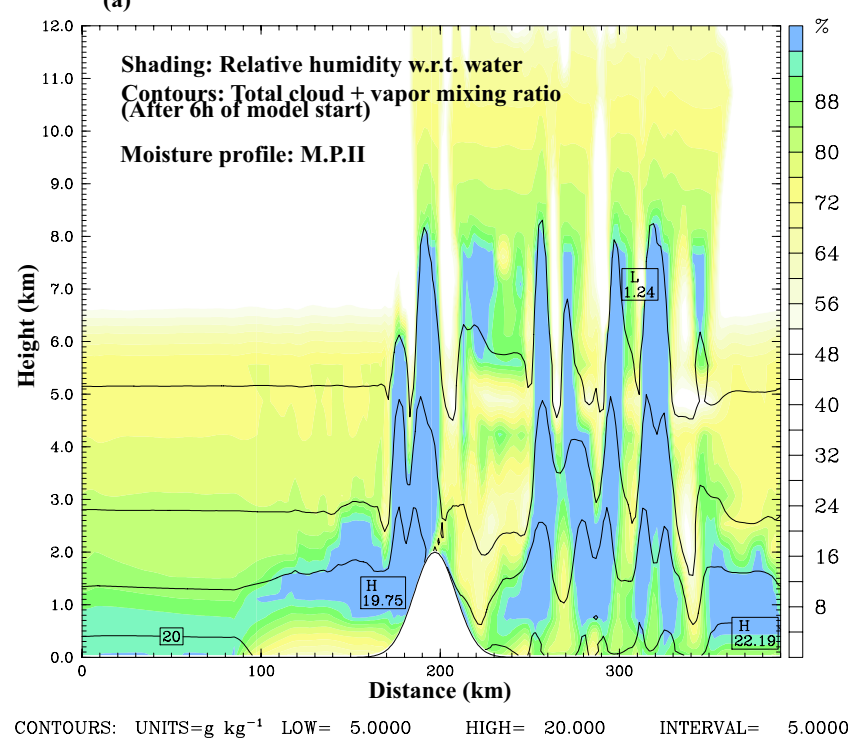

(b)

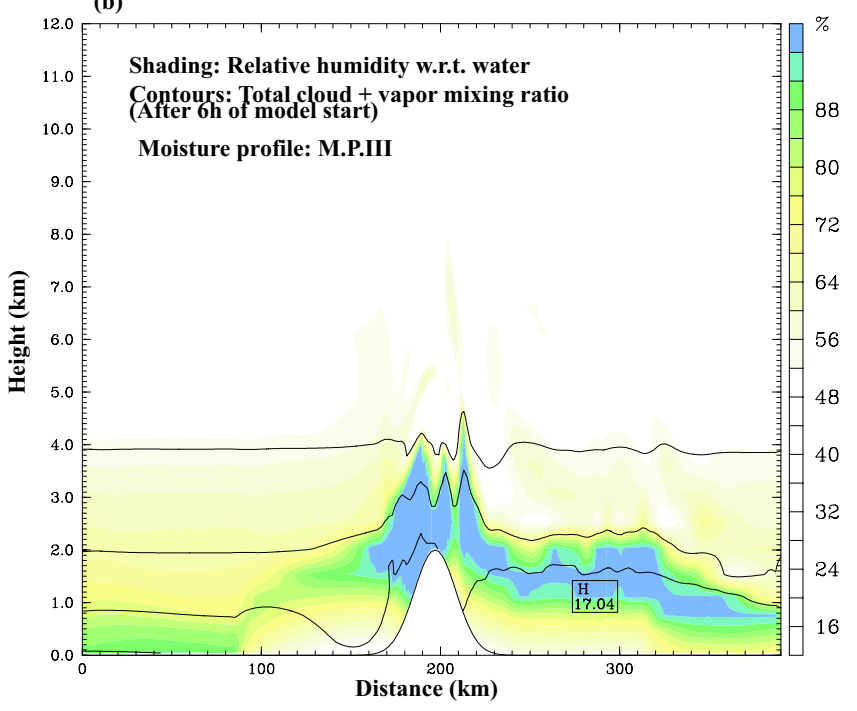

CONTOURS: $\quad$ UNITS $=\mathrm{g} \mathrm{kg}^{-1}$ LOW $=5.0000 \quad \mathrm{HIGH}=20.000 \quad$ INTERVAL $=5.0000$

Fig. 10. Relative humidity and total water in the air for case with moisture profile (a) M.P. II and (b) M.P. III.

(a)

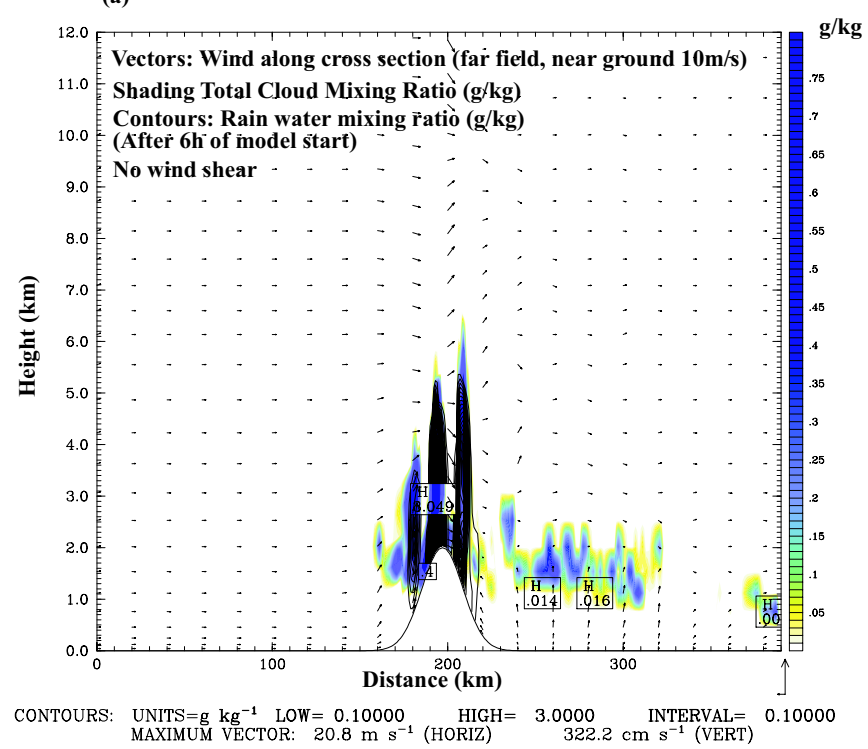

(b)

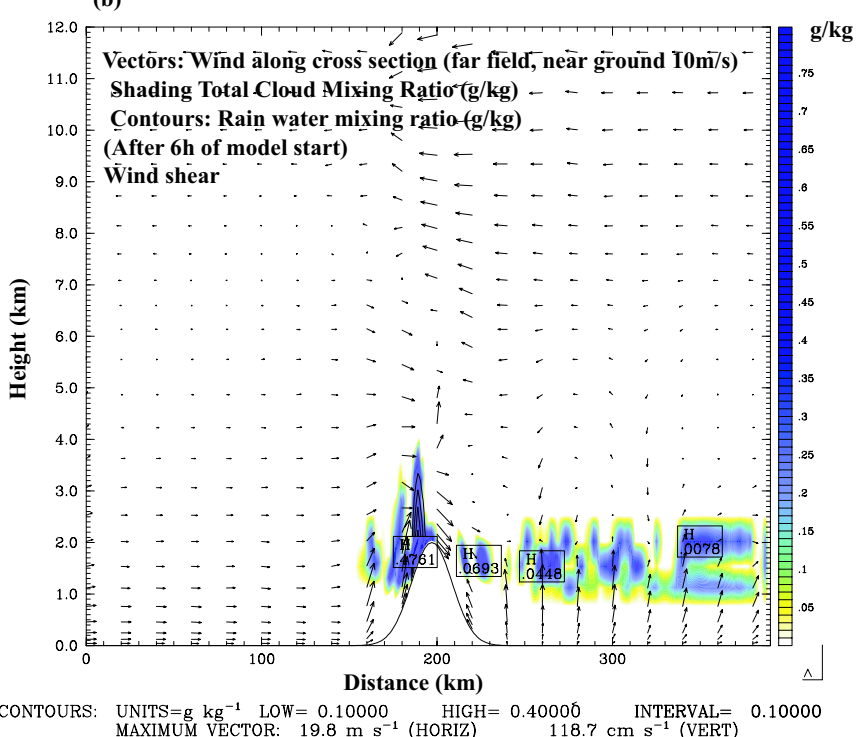

Fig. 11. Wind, clouds and rainfall after $6 \mathrm{~h}$ of model start for the case (a) without wind shear and (b) with wind shear in upper troposphere. Presence of wind shear limits the convective development and restricts rainfall to windward slope.

dry during the season. Figure 11 shows a comparison of clouds and rainfall after $6 \mathrm{~h}$ of model start, for cases with and without wind shear. It is clearly indicated that the presence of wind shear in troposphere restricts the overall development of convection and largely limits the convective activity to windward slope.

Finally, Fig. 5S-a shows the results of a simulation with no large-scale wind field. It should be noted that this particular simulation was done in a nested grid setup in order to provide about $200 \mathrm{~km}$ of ocean (as opposed to $80 \mathrm{~km}$ in the previous cases) on either side of the land. Due to the differential heating of ocean and land, the convergence of wind occurs over the ridge, causing small amounts of rainfall on and around the mountain peak. However, it is interesting to note that the rainfall yield is much smaller than the case with large-scale wind field and same moisture profile (M-b). This confirms the hypothesis that the second peak on the downstream is caused by the interaction of large-scale wind field with opposing sea-breeze - rather than a result of sea-breeze alone. 


\subsection{Boundary effects}

In order to economically use a 3-dimensional model to represent a dynamically 2-dimensional problem, a long, thin model domain $(200 \times 22$ grids $)$ was used. Since a five-cell thick relaxation zone was used on the sides, the effect of lateral wind shear due to the enforcing of boundary conditions on long sides of the domain is small. However, still the lateral boundary conditions may have certain effect on the rainfall simulations. Figure 12 shows plots of 24 haccumulations of rainfall along several longitudinal sections. The systematic differences of rainfall along $C(X-X$ in Fig. 2) and its neighboring lines $(C \pm 1)$, clearly show that even the central part of the domain feels the boundary effect. However, this does not prevent using the system for qualitative understanding of orographic rainfall. One other restrictive effect of the limited lateral size is the negative influence it may have on the mesoscale organization of the convective cells.

\section{Conclusions}

A number of idealized simulations of the atmosphere surrounding a single mountain ridge was done, with changing different model parameters. Most of the simulations agree with the common observations of increase of accumulated rainfall with altitude, relatively larger rainfall amounts on upwind slopes compared with downwind slopes and the occurrence of rainfall maxima on some distance upwind of the mountain peak. However, the exact distribution of rainfall is remarkably different among simulations with differing parameters. Convective activity at different locations seems to be the main contributor to the orographic rainfall. Sea-breeze interaction with the wind descending the slopes, caused convective rainfall on the leeward slopes and plains. Slow largescale wind speeds caused flow separations to occur more than $50 \mathrm{~km}$ upwind of the mountain, causing the incoming warmmoist air to rise in convection and produce large amounts of rainfall. Reduction of moisture reduced the rainfall volume as well as dispersion of rainfall towards the lee side. However, even with low moisture, lee slopes received a small amount of rainfall. Wind shear on middle troposphere acts to reduce the convective rise and therefore the rainfall and more importantly together with a low moisture profile, it seems to restrict the rainfall largely to the windward side.

Classical explanations of orographic rainfall often give prominence to the upslope condensation mechanism - the stable precipitating clouds created by moist air raised above the lifting condensation level by the forcing induced by the mountain topography. Though similar phenomena occurred during the simulations (mostly during morning times, or just after the start of the simulations - i.e. when the ground it not warm enough to produce low-level instability to aid convection, e.g. Fig. 3) they did not significantly contribute to the

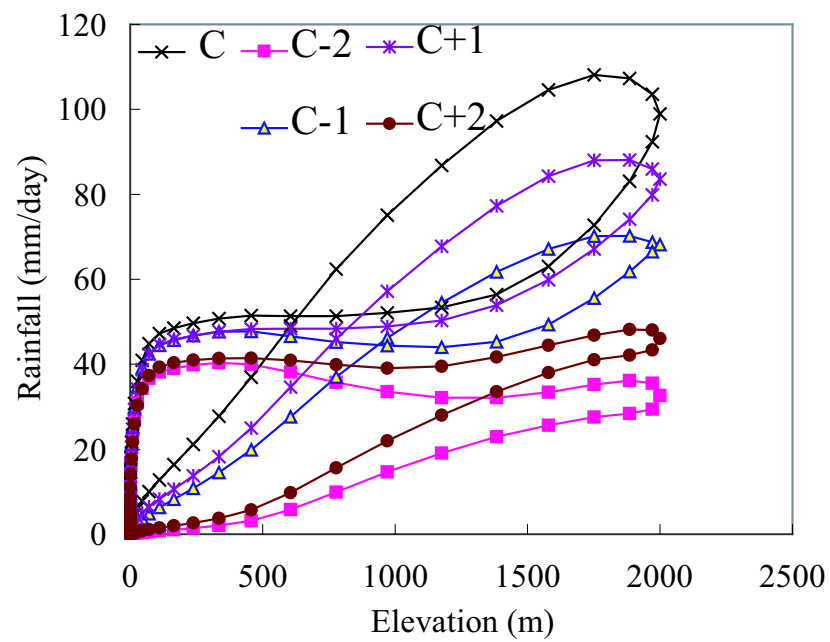

Fig. 12. Rainfall along several longitudinal sections (control-run). 'Standard' distribution along central line $X-X$ (see Fig. 2) is shown as $C$. $C+n$ indicates a section, $n$ cells north of central line.

rainfall yield. Instead, convective precipitation due to several different mechanisms was the main contributor.

Numerical simulations with idealized terrain and atmospheric forcing revealed a number of important features of the rainfall and associated atmospheric processes, related to the interaction of large-scale wind fields with a mountain ridge. The approach used was to systematically change a single model condition like ridge height, wind speed or moisture, while keeping others constant and to examine the resulting changes in atmospheric processes and rainfall. Due to the computational expense of the approach only a limited number of cases could be simulated. Hence, the effects of a number of other factors that are known to affect the results were not examined - landuse patterns, unsteady winds, three dimensional topography, to name a few. However, present simulations produced some useful insights into the orographic rainfall process that are not possible with only analytical studies.

Acknowledgements. This work was funded by a grant from the Japan Society for Promotion of Science during the period 2001-2003 and a grant from the CREST project of Japan Science and Technology Agency in 2004..

Edited by: J. Brandt

\section{References}

Doyle, J. D. and Durran, D. R.: The dynamics of Mountain-waveinduced rotors, J. Atmos. Sci., 59, 186-201, 2001.

Dudhia, J.: A non-hydrostatic version of the Penn State-NCAR Mesoscale Model: validation tests and simulation of an Atlantic Cyclone and cold front, Mon. Weather Rev., 121, 1493-1513, 1993. 
Durran, D. R. and Klemp, J.: A compressible model for the simulation of moist mountain waves, Mon. Weather Rev., 111, 23412361, 1986.

Durran, D. R. and Klemp, J. B.: On the effects of moisture on the Brunt-väisälä frequency, J. Atmos. Sci., 39, 2152-2158, 1982.

Flatau, P., Walko, R., and Cotton, W.: Polynomial fits to saturation vapor pressure, J. Appl. Meteorol., 31, 1507-1513, 1992.

Gossard, E. E.: Waves in the atmosphere: Atmospheric infrasound and gravity waves : their generation and propagation, Elsevier, New York, 1975.

Grell, G., Dudhia, J., and Stauffer, D.: A Description of the FifthGeneration Penn State/NCAR Mesoscale Model (MM5), Tech. Rep. NCAR/TN-398+STR, National Center for Atmospheric Research, 1996.

Hibino, T., Yamada, T., and Nakatsugawa, M.: Wind Field in Meso$\beta$ Scale Caused by Orographic Effect, in Proc. of XXV Congress of IAHR, Vol. I, pp. 135-142, 1993.

Holton, J. R.: An introduction to dynamic meteorology, Adademic press, New York, 3 Eedn., 1992.

Hong, S. and Pan, H.: Nonlocal boundary layer vertical diffusion in a medium-range forecast model, Mon. Weather Rev., 124, 2322 2339, 1996.

Houze, R. A. J.: Cloud Dynamics, chap. Orographic Clouds, pp. 502-538., Academic Press, 1993.

Leutbecker, M.: Terraini and Datagridi, ftp://ftp.ucar.edu/mesouser/ user-contrib/ideal.tar.gz, 1996.
Lin, Y., Farley, R. D., and Orville, H. D.: Bulk parameterization of the snow field in a cloud model, J. Clim. Appl. Meteor., 22, 1065-1092, 1983.

Nance, L. and Durran, D. R.: A modeling study of nonstationary trapped mountain lee waves, Part I: Mean flow variability, J. Atmos. Sci., 54, 2275-2291, 1997.

Nance, L. and Durran, D. R.: A modeling study of nonstationary trapped mountain lee waves, Part II: Nonlinearity, J. Atmos. Sci., 55, 1429-1445, 1998.

Pathirana, A., Yamaguchi, M., and Yamada, T.: Idealized simulation of airflow over a mountain ridge using a mesoscale atmospheric model, Annual Journal of Hydraulic Engineering, JSCE, 47, 31-36, 2003.

Pilke, R.: Mesoscale Meteorological Modeling, Academic Press, San Diego, California, 2 Edn., 2002.

Rögnvaldsson, Ó.: Idealgrid package, Article on WWW, http: //www.vedur.is/folk/olafurr/idealgrid/, 2002.

Smith, R.: Hydrostatic airflow over mountains, Adv. Geophys., 31, 1-41, 1989.

Smith, R. B.: The influence of mountains of the atmosphere, Adv. Geophys., 21, 87-230, 1979.

Tao, W., Simpson, J., and McCumber, M.: Ice-water saturation adjustment, Mon. Weather Rev., 117, 231-235, 1989.

Wallace, J. M. and Hobbs, P. V.: Atmospheric Science: An Introductory Survey, Adademic press, New York, 1977.

Zubair, L.: A dynamical model for orographic rainfall in Sri Lanka, in Proceedings of Asian Fluid Dynamics Congress, vol. 8, pp. 864-867, Shenzen, China, 1999. 